\title{
Line Transect and Triangulation Surveys Provide Reliable Estimates of the Density of Kloss' Gibbons (Hylobates klossii) on Siberut Island, Indonesia
}

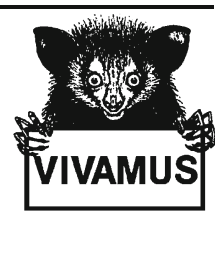

\author{
Andrea Höing • Marcel C. Quinten • \\ Yohana Maria Indrawati • Susan M. Cheyne • \\ Matthias Waltert
}

Received: 27 July 2012 / Accepted: 18 December 2012 /Published online: 8 January 2013

(C) Springer Science+Business Media New York 2013

\begin{abstract}
Estimating population densities of key species is crucial for many conservation programs. Density estimates provide baseline data and enable monitoring of population size. Several different survey methods are available, and the choice of method depends on the species and study aims. Few studies have compared the accuracy and efficiency of different survey methods for large mammals, particularly for primates. Here we compare estimates of density and abundance of Kloss' gibbons (Hylobates klossii) using two of the most common survey methods: line transect distance sampling and triangulation. Line transect surveys (survey effort: $155.5 \mathrm{~km}$ ) produced a total of 101 auditory and visual encounters and a density estimate of 5.5 gibbon clusters (groups or subgroups of primate social units) $/ \mathrm{km}^{2}$. Triangulation conducted from 12 listening posts during the same period revealed a similar density estimate of 5.0 clusters $/ \mathrm{km}^{2}$. Coefficients of variation of cluster density estimates were slightly higher from triangulation (0.24) than from line transects $(0.17)$, resulting in a lack of precision in detecting changes in cluster densities of $<66 \%$ for triangulation and $<47 \%$ for line transect surveys at the $5 \%$ significance level with a statistical power of $50 \%$. This case study shows that both methods may provide
\end{abstract}

\footnotetext{
A. Höing $(\triangle) \cdot$ M. Waltert

Department of Conservation Biology, Centre for Nature Conservation, Georg-August-Universität Göttingen, 37073 Göttingen, Germany

e-mail: hoeing.andrea@googlemail.com

M. C. Quinten

Department of Reproductive Biology, German Primate Center, 37077 Göttingen, Germany

Y. M. Indrawati

Institut Pertanian Bogor, Bogor Agricultural University, Bogor, 16680 West Java, Indonesia

S. M. Cheyne

Wildlife Conservation Research Unit, Department of Zoology, Oxford University, Tubney, Oxfordshire OX13 5QL, UK
} 
estimates with similar accuracy but that line transects can result in more precise estimates and allow assessment of other primate species. For a rapid assessment of gibbon density under time and financial constraints, the triangulation method also may be appropriate.

Keywords Auditory sampling $\cdot$ Hylobates klossii $\cdot$ Line transect survey $\cdot$ Mentawai islands $\cdot$ Siberut $\cdot$ Triangulation

\section{Introduction}

Reliable estimates of population sizes of target species are of central importance to many conservation programs. Density estimates provide baseline data on species abundance and allow the monitoring of population sizes, which is important in assessing the suitability of conservation strategies. However, few studies compare different survey methods and designs for large mammals under the same conditions, for instance, the same time of year and same location (Nijman and Menken 2005; Nomani et al. 2012; Viquerat et al. 2012). Such a comparison, however, can highlight strengths and weaknesses of the specific methods and thus provide useful information for conservation practitioners when deciding on the most suitable methods to deliver their conservation objectives.

One of the most common population assessment methods for diurnal primates is line transect sampling (Buckland et al. 2010). This method is known to be accurate if a small number of key assumptions are met. Best practice guidelines regarding survey design, field protocol, and analysis are available (Buckland et al. 2010) but several primatologists have discussed the possibility that this method is less efficient for some species, among them the members of the gibbon family Hylobatidae (Nijman and Menken 2005; Whittaker 2005; and see discussion in Waltert et al. 2008). Gibbons are small bodied arboreal apes found across eastern and southeastern Asia, Northwest India, and Bangladesh. In comparison to other primates, gibbons have distinctive behavioural characteristics, including regular vocal displays (Bartlett 2007). Morning calls are thought to function as territory defense as well as to strengthen the pair bond (Cheyne et al. 2008; Geissmann 2003). Owing to their otherwise inconspicuous behavior and their tendency to use the upper canopy (Nijman 2001), line transect surveys might fail to record $100 \%$ of individuals near the transect line, resulting in underestimation of population densities if no action is taken to accommodate the violation of this key assumption (Buckland et al. 2001, 2010).

Triangulation (also known as auditory sampling or fixed point counting) has recently become a commonly applied method to estimate gibbon densities and has proved to be both successful and time efficient (Brockelman and Ali 1987; Brockelman and Srikosamatara 1993; Buckley et al. 2006; Cheyne et al. 2008; Hamard et al. 2010; Nijman 2001; O’Brien et al. 2004). Further, triangulation is seen as the most applicable method in hilly terrain (Nijman and Menken 2005). Besides the obvious advantages, such as the fact that sampling does not affect gibbon behaviour toward the observer, triangulation can be performed within a relatively short time period and it is less destructive, as no transects need to be cut. It may, 
nevertheless, also introduce some sources of bias, e.g., through the influence of weather conditions on singing behavior or by underestimation of distances to calling groups, the latter of which may result in overestimation of densities (Cheyne et al. 2008; Nijman 2001). In addition, calling rates and data on cluster (groups or subgroups of primate social units) size are needed, requiring long-term data or extra survey effort. Triangulation alone does not ensure a sufficient number of sightings to estimate cluster size (Cheyne et al. 2008).

Here we compare line transect sampling with triangulation in estimating densities of Hylobates klossii in the Peleonan Forest, a mixed evergreen rainforest with hilly terrain in the north of Siberut island (Hadi et al. 2009), Indonesia. Hylobates klossii is endemic to the Mentawai Archipelago and is listed as endangered by IUCN (Whittaker and Geissmann 2008). If the two methods have comparable accuracy then the results for density estimates should not differ significantly.

\section{Methods}

\section{Study Site}

The Mentawai Archipelago is located $85-135 \mathrm{~km}$ west of the island of Sumatra, Indonesia. Siberut is the most northerly and largest island with an area of $4030 \mathrm{~km}^{2}$ (Whittaker 2006; Whitten 1982a). Close to the northern coast of Siberut lies the Peleonan Forest, which consists of a $45 \mathrm{~km}^{2}$ section of primary lowland and swamp forest (Quinten et al. 2010). The maximum elevation is $190 \mathrm{~m}$ above sea level and the area is characterized by hills and ridges that are covered by primary mixed evergreen rain forest (Hadi et al. 2009).

Pungut field station of the Siberut Conservation Programme (SCP) is located ( $1^{\circ} 01^{\prime \prime} \mathrm{S}$ and $98^{\circ} 50^{\prime \prime} \mathrm{E}$ ) in the south of the Peleonan Forest. We conducted this study in a circular area of $10.7 \mathrm{~km}^{2}$ around the field station. The transect system around the station consists of 13 systematically placed transects each 1-3 km in length (Waltert et al. 2008).

\section{Data Collection}

We conducted line transect sampling and triangulation of gibbons following Waltert et al. (2008) and Cheyne et al. (2008), respectively. We conducted triangulation at four different survey sites covering the study area of the SCP during 4 wk from September 8 until October 3, 2010. At each sample site we recorded compass bearings and estimated distance to gibbon calls. Although distance is not required for triangulation, we used the distance estimates to check that the same cluster was heard by two different listening posts. We checked distance estimates up to $900 \mathrm{~m}$ by moving from the listening post to the calling cluster using a Global Positioning System (Garmin GPSMap 60CSx).

We collected data from three listening posts situated in a triangle formation on elevated terrain. The distances between listening posts were 300-500 m. We collected data on four consecutive days at each site at 04:30-10:00 h. Observers stayed at the listening posts until the gibbons had stopped singing for $\geq 30 \mathrm{~min}$.

We conducted line transect surveys between 06:30-11:30 $\mathrm{h}$ and 15:30-18:00 $\mathrm{h}$ from September 14 and November 26, 2010. Protocols, season, survey times, 
surveyed transects, and data analysis followed those of the last survey in the study area in 2005 (Waltert et al. 2008). We surveyed each of the 13 transects around the field station between six and eight times (mean 7.23, $\mathrm{SD}=0.6$ ), resulting in a total survey effort of $155.5 \mathrm{~km}$.

Two teams, each consisting of two people, carried out line transect surveys. We documented all detections of primates, recording species, cluster size, and the perpendicular distance from the transect line to the estimated center of the cluster using a laser range finder (Nikon 550) for distances $>10 \mathrm{~m}$ and a tape measure for distances $<10 \mathrm{~m}$.

\section{Data Analysis}

We analyzed triangulation data following a triangulation protocol (Cheyne et al. 2008; Hamard et al. 2010). The triangulation method usually uses only duet counts for gibbons to ensure that a reproductive gibbon cluster is recorded (Brockelman and Srikosamatara 1993). However, unlike most gibbon species, male and female Hylobates klossii do not duet. Instead males can be heard to sing between 01:00 and 13:00 h, but concentrate mainly on the hours before dawn, whereas females sing after dawn (Whitten 1982b). We used only clusters that were recorded after dawn, i.e., those likely to be females, for analysis. We determined cluster size by mapping all sightings of gibbon clusters encountered during the entire study period. We then calculated the mean of the cluster sizes recorded for the mapped clusters. We assumed that individuals sighted $>300 \mathrm{~m}$ apart belonged to different gibbon clusters. For clusters encountered several times at the same location, we used the maximum number of individuals recorded as the size for that cluster. Owing to time constraints, we could not assess calling rates, so we assumed that females call every 3-4 d (Whitten 1982b). We aimed for $\geq 3 \mathrm{~d}$ survey at each site, but unfortunately this turned out not to be possible, owing to time constraints and weather conditions in one site where we obtained only 2 survey days.

We converted distance and compass bearing to $x, y$ coordinates and plotted them. Distance to the cluster is noted to aid data analysis if there are two clusters singing on the same compass bearing. This is a standard procedure (Cheyne et al. 2008; Hamard et al. 2010). Where there is no conflict in number of clusters on any given compass bearing, the compass directions only are plotted and intersections used to indicate clusters.

Previous research on Hylobates klossii estimated their home range to be 20-35 ha (Whitten 1982a), giving a circle of diameter 250-333 m. We, therefore, defined clusters $>300 \mathrm{~m}$ apart as different clusters. Those closer than $300 \mathrm{~m}$ are likely to represent double counting where gibbons moved between calling bouts. We took the number of clusters heard per day and the total number of clusters heard from each listening post from the maps.

We determined effective listening areas - the areas where a minimum of two listening posts could have heard gibbon calls, within a radius of $1000 \mathrm{~m}$ around each post - using ArcGIS 9.2. We calculated density estimates using the following formula and correction factors, assuming that singing on successive days is independent (Brockelman and Ali 1987; Cheyne et al. 2008).

Density estimate: $D=n /[p(m) \times E]$

and correction factor: $p(m)=1-[1-\mathrm{p}(1)]^{\mathrm{m}}$, 
where $n$ refers to the cumulative total number of clusters heard in the effective listening area $E$ at each site, $p(m)$ denotes the cumulative number of clusters singing in $m$ days, $p(1)$ refers to the mean of the proportion of clusters heard calling at each site (once the data from all study days were combined). We used SPSS 17.0 to calculate $95 \%$ confidence intervals (CI). We calculated coefficients of variation (CV) using the formula $\mathrm{CV}=\sigma / \mu$, where $\sigma$ denotes standard deviation and $\mu$ denotes mean.

We analyzed line transect data using Distance v. 6.0. (Thomas et al. 2010). We modelled detection functions using half-normal key functions with Hermite polynomial adjustment. We calculated expected cluster size from a size-biased regression of $\ln [$ cluster size] against estimated detection probability $g(x)$. Ideally surveys should be conducted using a systematic random design or a set of equally spaced transects randomly located in the survey region (Buckland et al. 2010). At Pungut, however, the trail system is oriented in a radial manner around the field station. To account for potential bias arising from overcoverage of the area directly surrounding the station, we stratified data in an inner circle with an area of $1.13 \mathrm{~km}^{2}$ (radius $=0.6 \mathrm{~km}$ ) and an outer belt of $9.55 \mathrm{~km}^{2}$. Because cluster density estimates did not differ significantly between stratified data and nonstratified data $(Z=-0.47, P=0.64)$ we present estimates from non-stratified data.

We compared cluster and individual density estimates between the two survey methods using a two-tailed $Z$-test. Further, we compared cluster sizes including lone males with those excluding lone males, using a two-tailed $Z$-test.

Further, we calculated resolution $R$ (minimum detectable change in population density) from both methods by using the formula $R=2.77 *(\mathrm{CV} / 100)$ for a significance level of $5 \%$ and a statistical power of $50 \%$ (Plumptre 2000).

\section{Results}

Triangulation resulted in a mean density estimate of 5.01 clusters $/ \mathrm{km}^{2}$ (95\% CI: $3.1-$ 6.9; Table I). Mean cluster size was estimated at 3.5 individuals/cluster excluding

Table I Parameters used to determine gibbon cluster densities at different sampling sites in the Peleonan forest, Siberut, Indonesia

\begin{tabular}{|c|c|c|c|c|c|c|}
\hline $\begin{array}{l}\text { Site } \\
\text { number }\end{array}$ & Clusters heard & $\begin{array}{l}p(1)(95 \% \\
\text { CI, CV })\end{array}$ & $p(m)$ & $m$ (days) & $E\left(\mathrm{~km}^{2}\right)$ & $\begin{array}{l}\text { Density } \\
\text { (clusters } / \mathrm{km}^{2} \text { ) }\end{array}$ \\
\hline 1 & 11 & $\begin{array}{r}0.5(-0.14- \\
1.14,0.14)\end{array}$ & 0.75 & 2 & 3.19 & 4.6 \\
\hline 2 & 17 & $\begin{array}{r}0.34(0.18- \\
0.5,0.29)\end{array}$ & 0.81 & 4 & 3.23 & 6.5 \\
\hline 3 & 15 & $\begin{array}{r}0.51(0.17- \\
0.86,0.27)\end{array}$ & 0.88 & 3 & 3.22 & 5.27 \\
\hline 4 & 10 & $\begin{array}{r}0.47(0.09- \\
0.85,0.33)\end{array}$ & 0.85 & 3 & 3.21 & 3.67 \\
\hline $\begin{array}{c}\text { Mean }(95 \% \\
\text { CI, CV })\end{array}$ & $\begin{array}{l}13.25(7.99- \\
18.51,0.25)\end{array}$ & $\begin{array}{r}0.46(0.33- \\
0.58,0.17)\end{array}$ & $\begin{array}{c}0.82(0.73- \\
0.91,0.07)\end{array}$ & $\begin{array}{l}3(1.70- \\
\quad 4.30,0.27)\end{array}$ & $\begin{array}{l}3.21(3.19- \\
3.24,0.005)\end{array}$ & $\begin{array}{r}5.01 .(3.12- \\
6.90,0.24)\end{array}$ \\
\hline
\end{tabular}

$p(1)$ mean of proportion of clusters calling vs. the total number of clusters identified over $m$ days with $95 \%$ $\mathrm{CI}$ and $\mathrm{CV} ; p(m)$ the cumulative number of cluster singing in $m$ days; $E$ effective listening area at each site. Mean values for all variables are given with $95 \% \mathrm{CI}$ and $\mathrm{CV}$ 
lone gibbons ( $N=27,95 \% \mathrm{CI}: 2.8-4.3)$ and 3.0 individuals/cluster $(N=34,95 \% \mathrm{CI}$ : 2.3-3.7) including lone gibbons. Those cluster sizes did not differ significantly from each other $(Z=0.19, P=0.85)$. Maximum recorded cluster size was eight, which we observed on three different occasions. The individual density estimate was 17.5 individuals $/ \mathrm{km}^{2}$ (95\% CI: 10.9-24.2) excluding lone males.

We recorded 101 observations of Hylobates klossii during line transect sampling, including auditory and visual records. A subset of 62 observations from truncation distance data at $92 \mathrm{~m}$ provided a good model fit, as did truncation to $42 \mathrm{~m}$ (Fig. 1).

We estimated cluster size from observed clusters as 2.7 individuals/cluster $(95 \%$ CI: 2.3-3.2 individuals/cluster), cluster density as 5.5 clusters $/ \mathrm{km}^{2}$ (95\% CI: 3.9-7.7/ $\mathrm{km}^{2}$ ) and individual density as $14.89 / \mathrm{km}^{2}$ (95\% CI: $10.2-21.7 / \mathrm{km}^{2}$; Table II).

There were no significant differences in cluster $(Z=-0.32, P=0.75)$ nor in individual density estimates $(Z=0.53, P=0.6)$ between triangulation and line transect methods.
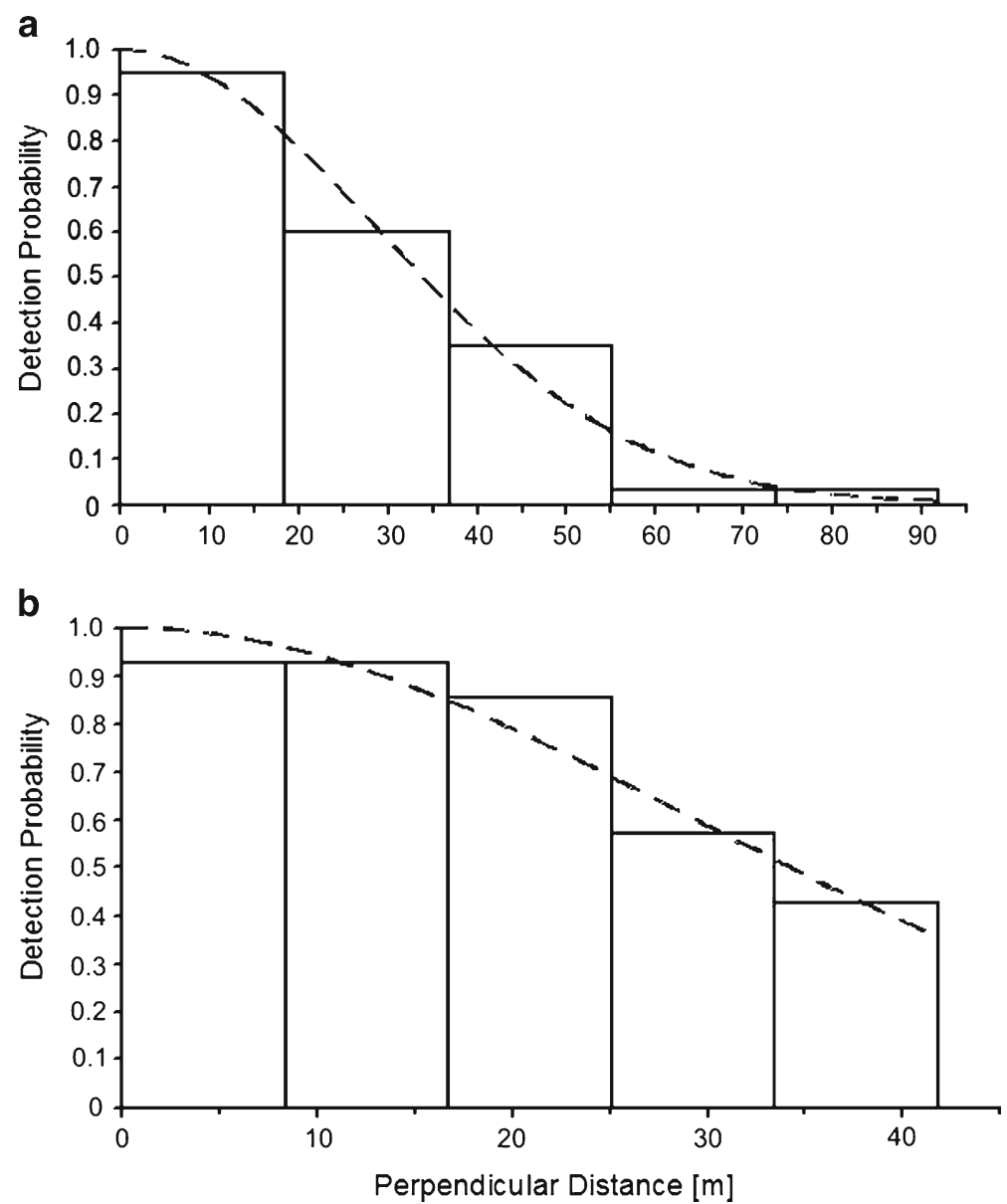

Fig. 1 Detection probability plot from line transect data (histograms) conducted for Hylobates klossii between September 14 and November 26, 2010 in the Peleonan forest, Siberut, Indonesia, and fitted detection function for truncation widths $w=92 \mathrm{~m}$ (a) and $w=42 \mathrm{~m}(\mathbf{b})$. 
Table II Estimates, after data truncation, of encounter rate, cluster density, and expected cluster size, as well as detection probability (probability of observing a cluster within $w[\mathrm{~m}]$ from the transect line) with $95 \%$ CI for Hylobates klossii from line transect sampling in the Peleonan forest, Siberut, Indonesia

Mean encounter rate of clusters/ $\mathrm{km}(95 \% \mathrm{CI}, \mathrm{CV})$

Expected cluster size (95\% CI, CV)

Mean cluster density $/ \mathrm{km}^{2}$ (95\% CI, CV)

Detection probability (95\% CI, CV)

Truncation distance $w[\mathrm{~m}]$

Number of observations $N$

Mean density, individuals $/ \mathrm{km}^{2}$ (95\% CI, CV)
$0.40(0.30-0.54,0.15)$

$2.7(2.3-3.2,0.09)$

$5.5(3.9-7.7,0.17)$

$0.39(0.33-0.46,0.08)$

92

62

$14.9(10.2-21.7,0.19)$

All estimates for truncation distance $(w)$ from number of observations of clusters $(N)$. Mean individual density estimates with $95 \% \mathrm{CI}$ and coefficient of variation $\mathrm{CV}$

The CV for cluster densities was 0.24 for triangulation and 0.17 for line transects. Thus, changes in cluster densities of $R<66 \%$ at a significance level of $5 \%$ with a statistical power of $50 \%$ are unlikely to be detected using the triangulation method. For line transect surveys, changes in cluster densities are unlikely to be detected if $R<47 \%$ at a significance level of $5 \%$ with a statistical power of $50 \%$.

\section{Discussion}

We found no difference in our estimations of cluster or individual densities using triangulation and line transect sampling and therefore may assume similar accuracy from both methods. The true number of gibbons present in the area, however, is unknown, as is also the proportion of lone gibbons in the area, so we cannot correct individual density estimates gained by triangulation for this potential bias (Cheyne et al. 2008). Both methods used may underestimate individual density slightly. We also do not know the levels of under-recording of lone gibbons and those close to observers. Nevertheless, the detection probability plot showed a prominent shoulder when truncating to $42 \mathrm{~m}$, suggesting no under-recording near the transect line (Fig. 1b).

Gibbon densities assessed by triangulation in our study area in 2003 resulted in density estimates of $>25$ individuals $/ \mathrm{km}^{2}$ (Whittaker 2005), $50 \%$ higher than estimates obtained from line transect surveys in 2005 (Waltert et al. 2008). However, this difference is due mainly to an exceptionally high estimate of mean cluster size in the triangulation study (mean cluster size 10 from $N=8$ observations; Whittaker 2005). Our mean cluster size for all gibbon cluster sightings used for triangulation (3.5 individuals) was similar to the mean cluster sizes in previous studies (3.4 individuals: Tenaza 1975; 3.7 individuals: Whitten 1982a). This suggests that more than eight sightings are needed to estimate cluster size (perhaps $N>20$ ). If cluster size cannot be estimated accurately, we suggest using cluster density estimates instead of individual density estimates to compare results from different studies or from different survey methods.

Although the two methods gave similar estimates of gibbon densities, line transect sampling resulted in more precise cluster density estimates, allowing better detection of changes over time. Even if search effort is optimal, the line transect method is unlikely to detect changes of $<25-30 \%$ (Plumptre and Cox 2006) whereas indirect methods, such as 
nest, dung, or cue surveys, are suggested to be unlikely to detect changes of $<30-50 \%$ (Buckland et al. 2001; Plumptre 2000). We conducted surveys over a relatively long time period (triangulation $4 \mathrm{wk}$; line transect surveys $10.5 \mathrm{wk}$ ); nevertheless we found that only much larger changes in densities than the ones suggested for optimal searching effort could be detected using either method. As time and funding are often limiting factors in small conservation projects, it is important that neither method may detect small changes $(<45 \%)$ in population densities even if search effort is relatively high.

The recommended number of observations to detect population changes over time is 100 (Plumptre 2000), which confirms that our line transect sampling effort is not optimal to observe changes. Our sampling effort may also have been too low for the triangulation. The likelihood of calling over all survey days should be at least 1 to detect all clusters present in the study area during triangulation. For example, a minimum of 5 consecutive days of sampling at each site are suggested for Hylobates agilis (O'Brien et al. 2004) and Hylobates albibarbis (Cheyne et al. 2008). Female Hylobates klossi sing every 3-4 d (Whitten 1982b), or even less frequently (Keith et al. 2009). Thus, the $2-4 \mathrm{~d}$ we spent at each site might have led to an underestimation of cluster densities.

Overall, we conclude that triangulation can yield density estimates that are not significantly different from those given by line transect sampling in primary lowland rain forests. The method of choice will depend on the objectives of the study and should take into account the terrain. Lowland forests with low elevation changes are probably best surveyed using triangulation. Triangulation was effective in monitoring changes in population densities over time in Hylobates albibarbis across Kalimantan (S. M. Cheyne pers. comm.). However, we suggest that line transect sampling is preferable for studies that focus on monitoring relatively small changes in population densities over time, because of its more precise estimates. Line transect sampling should also be chosen if a survey targets more than one species. If the objective of the study is to conduct rapid density estimates within a limited amount of time, in an area that is difficult to access, and/or if resources (human, funding) are limited, then triangulation might be more appropriate.

Acknowledgments Fieldwork was financially supported by the Primate Society of Great Britain (PSGB) and a scholarship of the German Academic Exchange Service, Deutscher Akademischer Austauschdienst (DAAD). It was also logistically supported by the German Primate Center, Deutsches Primaten Zentrum (DPZ). M. Waltert is currently supported by a grant from VolkswagenFoundation, Hanover, Germany.

We gratefully acknowledge the contribution of all the guides and staff from Pungut who contributed to the project: Pak Dodo, Pak Tarzan, Pak Bitcar, Pak Binson, Pak Aser, Pak Amsal, and Pak Teiba. We thank the Indonesian Ministry of Science and Technology and the Indonesian Department of Forestry for permission to conduct research in the Siberut Island and the Agricultural University of Bogor (IPB) for sponsoring this research and providing invaluable logistical support. We are grateful for the helpful comments of the editor-in-chief and two reviewers for their constructive comments to improve the quality of the manuscript. We further acknowledge Dr. Sara Munday, Sophie Curtis, and Irendra Radjawali for their invaluable comments on the manuscript.

\section{References}

Bartlett, T. Q. (2007). The Hylobatidae-small apes of Asia. In C. J. Campbell, A. Fuentes, K. C. MacKinnon, M. Panger, \& S. Bearder (Eds.), Primates in perspective (pp. 274-289). New York: Oxford University Press.

Brockelman, W. Y., \& Ali, R. (1987). Methods of surveying and sampling forest primate populations. In C. W. Marsh \& R. A. Mittermeier (Eds.), Primate conservation in the tropical rain forest (pp. 23-62). New York: Liss. 
Brockelman, W. Y., \& Srikosamatara, S. (1993). Estimation of density of gibbon groups by use of loud songs. American Journal of Primatology, 29(2), 93-108.

Buckland, S. T., Anderson, D. R., Burnham, K. P., Laake, J. L., Borchers, D. L., \& Thomas, L. (2001). Introduction to Distance sampling: Estimating abundance of wildlife populations. Oxford: Oxford University Press.

Buckland, S. T., Plumptre, A. J., Thomas, L., \& Rexstad, E. A. (2010). Design and analysis of line transect surveys for primates. International Journal of Primatology, 31(5), 833-847.

Buckley, C., Nekaris, K. A. I., \& Husson, S. J. (2006). Survey of Hylobates agilis albibarbis in a logged peat-swamp forest: Sabangau catchment, Central Kalimantan. Primates, 47(4), 327-335.

Cheyne, S. M., Thompson, C. J. H., Phillips, A. C., Hill, R. M. C., \& Limin, S. H. (2008). Density and population estimate of gibbons (Hylobates albibarbis) in the Sabangau catchment, Central Kalimantan, Indonesia. Primates, 49(1), 50-56.

Geissmann, T. (2003). Vergleichende Primatologie. Berlin: Springer.

Hadi, S., Ziegler, T., Waltert, M., \& Hodges, J. K. (2009). Tree diversity and forest structure in northern Siberut, Mentawai islands, Indonesia. Journal of Tropical Ecology, 50, 315-327.

Hamard, M., Cheyne, S. M., \& Nijman, V. (2010). Vegetation correlates of gibbon density in the peat swamp forest of the Sabangau catchment, Central Kalimantan, Indonesia. American Journal of Primatology, 72(7), 607-616.

Keith, S. A., Waller, M. S., \& Geissmann, T. (2009). Vocal diversity of Kloss's gibbons (Hylobates Klossii) in the Mentawai Islands, Indonesia. In S. Lappan \& D. J. Whittaker (Eds.), The Gibbons. Developments in Primatology: Progress and Prospects (pp. 51-71). New York: Springer.

Nijman, V. (2001). Effect of behavioural changes due to habitat disturbance on density estimation of rain forest vertebrates, as illustrated by gibbons (Hylobatidae). In P. J. M. Hillegers \& H. H. DeIongh (Eds.), The balance between biodiversity conservation and sustainable use of tropical rain forests (pp. 217-225). Wageningen: Tropenbos.

Nijman, V., \& Menken, S. B. J. (2005). Assessment of census techniques for estimating density and biomass of gibbons (Primates: Hylogbatidae). Raffles Bulletin of Zoology, 53, 201-211.

Nomani, S. Z., Oli, M. K., \& Carthy, R. R. (2012). Line transects by design: The influence of study design, spatial distribution and density of objects on estimates of abundance. Open Ecology Journal, 5, 25-44.

O’Brien, T. G., Kinnaird, M. F., Nurcahyo, A., Iqbal, M., \& Rusmanto, M. (2004). Abundance and distribution of sympatric gibbons in a threatened Sumatran rain forest. International Journal of Primatology, 25(2), 267-284.

Plumptre, A. J. (2000). Monitoring mammal populations with line transect techniques in African forests. Journal of Applied Ecology, 37(2), 356-368.

Plumptre, A. J., \& Cox, D. (2006). Counting primates for conservation: Primate surveys in Uganda. Primates, 47(1), 65-73.

Quinten, M. C., Waltert, M., Syamsuri, F., \& Hodges, J. K. (2010). Peat swamp forest supports high primate densities on Siberut Island, Sumatra, Indonesia. Oryx, 44(1), 147.

Tenaza, R. (1975). Territory and monogamy among Kloss' gibbons (Hylobates klossii) in Siberut Island, Indonesia. Folia Primatologica, 24(1), 60-80.

Thomas, L., Buckland, S. T., Rexstad, E. A., Laake, J. L., Strindberg, S., Hedley, S. L., Bishop, J. R. B., Marques, T. A., \& Burnham, K. P. (2010). Distance software: Design and analysis of distance sampling surveys for estimating population size. Journal of Applied Ecology, 47(1), 5-14.

Viquerat, S. M. A., Bobo, K. S., Muller, M., Kiffner, C., \& Waltert, M. (2012). Estimating forest duiker (Cephalophinae) density in Korup National Park: A case study on the performance of three line transect methods. South African Journal of Wildlife Research, 42(1), 1-10.

Waltert, M., Abegg, C., Ziegler, T., Hadi, S., Priata, D., \& Hodges, K. (2008). Abundance and community structure of Mentawai primates in the Peleonan forest, north Siberut, Indonesia. Oryx, 42(3), 375-379.

Whittaker, D. J. (2005). New population estimates for the endemic Kloss's gibbon Hylobates klossii on the Mentawai Islands, Indonesia. Oryx, 39(4), 458-461.

Whittaker, D. J. (2006). A conservation action plan for the Mentawai primates. Primate Conservation, 20, 95-105.

Whittaker, D. J., \& Geissmann, T. (2008). Hylobates klossii. In IUCN 2010: IUCN Red List of Threatened Species, Version 2010.4. http://www.iucnredlist.org. Accessed February 18, 2011.

Whitten, A. J. (1982a). Home range use by Kloss gibbons (Hylobates klossii) on Siberut Island, Indonesia. Animal Behaviour, 30(1), 182-198.

Whitten, A. J. (1982b). The ecology of singing in Kloss gibbons (Hylobates klossii) on Siberut Island, Indonesia. International Journal of Primatology, 3(1), 33-51. 